\title{
CONTRASTACIÓN DE UN MODELO DE CULTURA ORGANIZACIONAL EN UNIVERSIDADES PÚBLICAS DEL CENTRO DE MÉXICO
}

\author{
Cruz García Lirios \\ Universidad Autónoma del Estado de México
}

\begin{abstract}
Resumen.- Grosso modo, la cultura organizacional ha sido definida en referencia a un conjunto de normas y valores, usos y costumbres en torno a un estilo de dirección tradicional, liderazgo unidireccional y clima de relaciones verticales. A partir de este modelo, nuevas culturas alternativas emergieron en respuesta al autoritarismo organizacional, pero la diversidad de propuestas ha generado factores e indicadores no siempre compatibles con las contingencias del entorno organizacional. El objetivo del presente trabajo es contrastar las trayectorias de relaciones de dependencia entre las variables que configuran la cultura organizacional en Instituciones de Educación Superior (IES) del centro de México. Se realizó un estudio transversal y exploratorio con una selección de 320 estudiantes, docentes y administrativos. Los resultados advierten la prevalencia de cuatro factores, tres los cuales se modelaron para predecir el habitus organizacional. Se advierten líneas de investigación relativas a las redes de conocimiento como factores que no sólo determinen la dinámica organizacional sino, además la transformen.
\end{abstract}

Palabras clave: Cultura, modelo, hipermetropía, habitus, indefensión, gobernanza

\section{Contrastation of a model of organizational culture in public universities of the center of Mexico}

Abstract.- Roughly, the organizational culture has been defined in reference to a set of norms and values, uses and customs around a traditional style of leadership, unidirectional leadership and climate of vertical relations. From this model, new alternative cultures emerged in response to organizational authoritarianism, but the diversity of proposals has generated factors and indicators that are not always compatible with the contingencies of the organizational environment. The objective of the present work is to compare the trajectories of dependency relations among the variables that make up the organizational culture in Institutions of Higher Education (IES) in central Mexico. A transversal and exploratory study was carried out with a selection of 320 students, teachers and administrators. The results indicate the prevalence of four factors, three of which were modeled to predict the organizational habitus. Lines of research related to knowledge networks are seen as factors that not only determine the organizational dynamics but also transform it.

Keywords: Culture, model, hypermetropy, habitus, defenselessness, governance

\section{INTRODUCCIÓN}

El objetivo del presente trabajo es contrastar un modelo de cultura laboral en el marco de las políticas de evaluación, acreditación y certificación de la calidad de los procesos y los productos en universidades públicas del centro de México, mediante el establecimiento de la confiabilidad y la validez de un instrumento que mide la cultura organizacional en una Institución de Educación Superior afiliada a la Asociación Nacional de Facultades y Escuelas de Contaduría y Administración (ANFECA). 
Una encrucijada es una situación en la que es posible elegir entre dos opciones que, sin embargo, ambas son desfavorables en el devenir histórico de un proceso como el del sistema educativo (Austrolakis, 2013).

En este sentido, los orígenes de tal encrucijada pueden ser diversos, empero al estar sumamente vinculados, Estado e IES son actores centrales de una trama que cobra tintes de una encrucijada y ante la cual es posible anticipar escenarios fatalistas como el de la rectoría del Estado, la calidad de vida y el bienestar subjetivos reducidos todos ellos a su mínima expresión.

Desde la teoría de los sistemas, los procesos están en constante movimiento, pero en función de un propósito explícito: el crecimiento. A partir de una lógica: la ganancia. Mediante una técnica específica: la elección racional (Ostrom, 2014).

Al decir que el sistema educativo está en una encrucijada es menester considerar el biopoder que supone una exclusión, ya que en todo sistema la entrada de información es procesada de un modo tal que genera un nuevo subsistema, independiente de la relación centro-periferia que le dio origen.

De este modo, la encrucijada es resultado del ejercicio sistemático de un biopoder que pretendió, a través del institucionalismo, el isomorfismo, el patrimonialismo y el credencialismo determinar la vida de estudiantes, docentes y administrativos en las IES.

Esto es así porque los sistemas no sólo producen dilemas de suma cero, sino además porque inhiben las relaciones de ganar-ganar.

En el caso del sistema educativo, la exclusión sólo es el resultado del juego entre dos actores que buscan un beneficio propio y no mutuo. Cuando tal sistema aproxima a los actores a un beneficio común, este se disuelve o es suplantado por otro sistema aún más excluyente (Corral y Pinheiro, 2009).

En este sentido, el biopoder es una lógica e instrumento de dominación orientado al beneficio de un solo actor sin importar la contribución de otros actores en los procesos en los que estén inmersos.

Se trata de un factor multiplicador de la información, es decir que cuando un actor propicia información concerniente a otros actores, no sólo reduce o limita sus capacidades de discernimiento, sino además difunde significados de amenazas potenciales a su persona (Rohrmann, 2000).

Precisamente, un sistema como el educativo genera una calidad de vida indicada por satisfactores y recursos, pero no siempre acompañada de un bienestar-percepción de beneficios ante costos probables-.

En el contexto de la Tecnologías de Información y Comunicación (TIC's) donde la información es un valor capital, los sistemas educativos en general y las IES en lo particular transitan de la evaluación, acreditación y certificación sin criterios de validez (Corraliza, 2001).

Los casos de fraudes en repositorios son ejemplos de cómo la información genera una calidad de vida informativa -accesibilidad, especialización y actualización-, pero no siempre un bienestar subjetivo o compartido -información útil con tecnología o dispositivos electrónicos exclusivos-. 
Por consiguiente, la encrucijada de las IES está en la información digitalizada y el impacto en la calidad de sus procesos y productos.

No obstante que los sistemas educativos se dirimen en su dimensión informativa y por ende en el establecimiento de agendas, su relevancia está en la amenaza principal de la humanidad: el cambio climático y sus efectos en la salud pública.

La encrucijada del sistema educativo también supone reducir la desesperanza ante los efectos del cambio climático en la salud pública, o bien, incrementar las expectativas en torno a la ciencia y la tecnología como instrumentos de solución provisionales de los desastres naturales y catástrofes ambientales (Embar, 2002).

Empero, las esperanzas en la ciencia y la tecnología están asociadas en la formación de generaciones para el mantenimiento de sistemas sustentables. Los escenarios demandan cada vez un comportamiento específico determinado por la cognición que suponen las creencias, las actitudes, los motivos y las intenciones.

En la terminología del Desarrollo Sustentable y el comportamiento humano favorable a la conservación de los recursos, un micro-ambiente es aquel en el que la calidad de los procesos educativos consiste en la preservación de la calidad de vida residencial (García et al., 2013).

De este modo, en casas habitación, oficinas y aulas donde se puedan generar propuestas de aprendizaje orientadas a la conservación del medio ambiente, la información y las creencias son factores determinantes de desarrollo.

Precisamente, es en los micro-ambientes donde se producen las iniciativas para establecer escenarios de proximidad al cuidado de patrimonios tales como los parques o plazas donde las identidades no sólo se recrean sino además deliberan y establecen consensos.

La formación de los valores y las capacidades en los micro-entornos y de proximidad determinan la gobernabilidad de ciudades y este desarrollo local impacta globalmente a las demás urbes (García, 2004).

Sin embargo, la encrucijada de la educación no estriba en la promoción de un crecimiento con tasa cero de emisiones de bióxido de carbono. Más bien está en la promoción de la calidad y el bienestar a partir de una adecuada comunicación de riesgos a partir de la cual los usuarios de esta información tomaran decisiones y acciones orientadas a la reducción de su consumo.

Si las personas están informadas en cuanto a las amenazas de su entorno y además son formadas con las habilidades, valores y conocimientos para la reducción de accidentes y la prevención de enfermedades, entonces aspiraran a una mejor calidad de vida siempre que anticipen escenarios fatalistas y construyan escenarios optimistas, pero en la promoción de la salud ocupacional, el bienestar subjetivo está más próximo al estrés o al síndrome el trabajo excesivo.

Por consiguiente, es menester observar las diferencias y similitudes entre los sistemas educativos que se orientan a la calidad de vida, pero en detrimento del bienestar subjetivo.

En virtud de que la calidad de vida no refiere a los aspectos intangibles tales como motivación, valores y normas, la ética del desarrollo se aleja de aquellas 
propuestas en donde más se considera que la acción individual se sume a otras iniciativas y configuren una respuesta inmediata ante las problemáticas esgrimidas.

La encrucijada de la educación va más allá de sus evaluaciones, certificaciones y aacreditaciones con respecto a las políticas públicas del Estado rector o posburocrático.

Si bien es cierto que tales problemáticas se abordan desde lo local, una respuesta global al cambio climático estaría indicada por la ética con la que se asumen antes de formar a estudiantes capaces de revertir la huella ecológica (Leal, 2014).

Se trata de una economía ecológica en la que los bienes ni son privados ni son públicos sino más bien comunes. La distinción entre crecimiento sostenido y desarrollo sustentable estriba en que la planificación de la producción, entradas y salidas de energía, se realiza con base en la perspectiva de mediano y largo plazo.

El sistema educativo al promover los bienes privados incide en las decisiones y acciones que hacen más competitivo al sistema y sus actores, al formar estudiantes desde la administración y la gestión pública generó propuestas dependientes de liderazgos en detrimento de la creatividad de los demás actores.

Empero, al establecer un proceso de enseñanza y aprendizaje acorde a la ética de los bienes comunes, el comportamiento en función de la disponibilidad de los recursos y la cultura organizacional de contingencias, las IES formarán estudiantes capaces de anticipar escenarios de escasez y exclusión, así como producir escenarios de sustentabilidad e inclusión.

Por lo tanto, el estudio de la encrucijada del sistema educativo está delimitado a lo local, organizacional, escolar y residencial siempre que a partir de estos escenarios se proyecten estrategias de difusión para una respuesta global al cambio climático (véase tabla 1).

Tabla 1. Dimensiones para el estudio de la encrucijada de los sistemas educativos

\begin{tabular}{|c|c|c|c|}
\hline Dimensión & Cambio climático & Salud pública & $\begin{array}{l}\text { Sistemas } \\
\text { educativos }\end{array}$ \\
\hline $\begin{array}{l}\text { Micro } \\
\text { Proximidad }\end{array}$ & $\begin{array}{l}\text { Hipermetropía: } \\
\text { percepciones } \\
\text { sesgadas acerca del } \\
\text { impacto de los } \\
\text { desastres naturales y } \\
\text { las catástrofes } \\
\text { ambientales sobre la } \\
\text { calidad de vida y el } \\
\text { bienestar subjetivo. }\end{array}$ & $\begin{array}{l}\text { Indefensión: } \\
\text { percepciones de } \\
\text { desesperanza en torno a } \\
\text { la contribución de } \\
\text { acciones personales } \\
\text { como respuesta ante el } \\
\text { cambio climático y sus } \\
\text { efectos en la salud } \\
\text { pública. }\end{array}$ & $\begin{array}{l}\text { Habitus: } \\
\text { disposiciones } \\
\text { heredadas } \\
\text { aprendidas, } \\
\text { favorables al al } \\
\text { cuidado de la } \\
\text { residencia, el aula, } \\
\text { la oficina o el taller } \\
\text { como ahorro } \\
\text { energético } \\
\text { hídrico, reutilización } \\
\text { de materiales y } \\
\text { tratamiento de } \\
\text { residuos. }\end{array}$ \\
\hline
\end{tabular}

Local Gobernanza: Gobernanza: Gobernanza: 


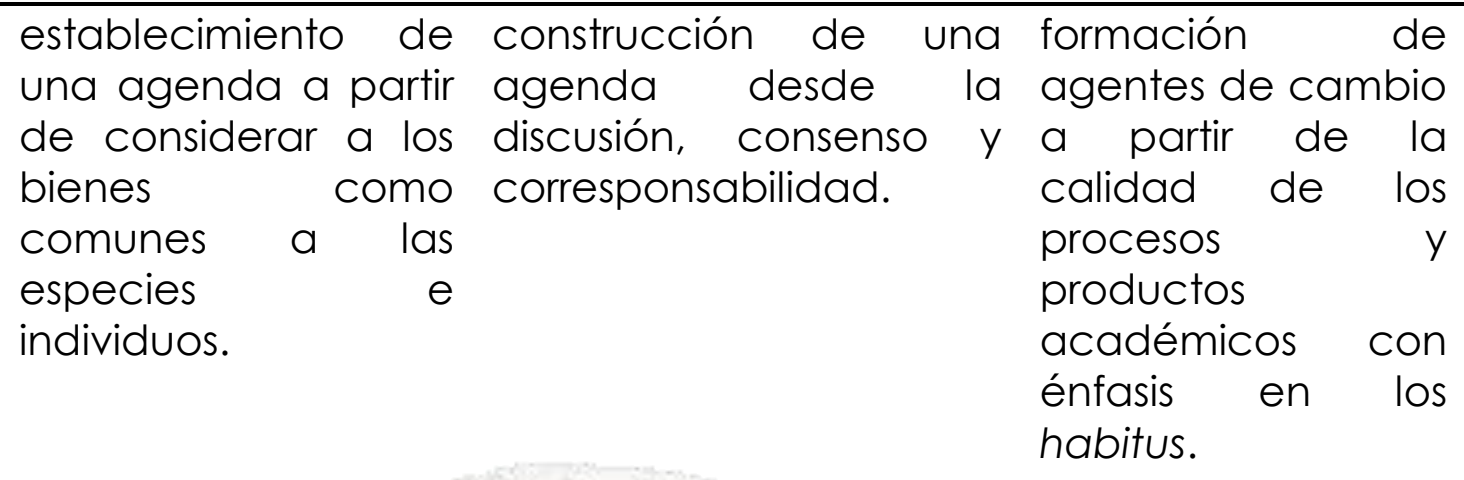

Fuente: Elaboración propia

Es posible observar que la encrucijada de la educación subyace de la hipermetropía, la indefensión y el habitus en relación con la gobernanza.

La hipermetropía supone la formación de estudiantes con habilidades, conocimientos y valores orientados a la cooperación, solidaridad y altruismo.

En contraste, la indefensión estriba en la medición de recursos que previenen los accidentes y anticipan enfermedades sin considerar el consumo ético que la hipermetropía enfatiza.

El habitus no sólo es resultado de las asimetrías entre los actores, además son estilos de vida cotidianos y pragmáticos que desvinculan a los sistemas porque cada individuo es independiente de ellos.

Hipermetropía, indefensión y habitus resaltan la complejidad de una gobernanza o gobierno de redes y esferas civiles.

Por consiguiente, la encrucijada es la cristalización de la complejidad que supone la construcción de una gobernanza.

No obstante que la gobernanza es una propuesta idónea para el estudio y la anticipación de los efectos del cambio climático sobre la salud y la educación, la especificación de un gobierno de redes y esferas civiles implica procesos cognitivos que emergen de la propaganda informativa neoconservadora y neoliberal (véase tabla 2).

Tabla 2. Dimensiones sociales para el estudio de la encrucijada educativa

\begin{tabular}{|c|c|c|c|}
\hline Dimensión & Propaganda & Agenda & Capacidades \\
\hline Hipermetropía & $\begin{array}{lr}\text { El Estado difunde su } \\
\text { poder mediante la } \\
\text { legitimidad } \\
\text { justificación de su } \\
\text { rectoría en materia } \\
\text { de evaluación, } \\
\text { certificación r y } \\
\text { acreditación, pero } \\
\text { docentes } \\
\text { estudiantes } \\
\text { reaccionan } \\
\text { percepciones }\end{array}$ & $\begin{array}{l}\text { La propaganda del } \\
\text { Estado, diseminada } \\
\text { en los medios de } \\
\text { comunicación } \\
\text { establece temas } \\
\text { que la sociedad } \\
\text { civil considera } \\
\text { relevantes para su } \\
\text { calidad de vida y } \\
\text { bienestar subjetivo, } \\
\text { pero no a través }\end{array}$ & $\begin{array}{lr}\text { La formación de } & \text { dabilidades } \\
\text { ha } & \text { conocimientos a } \\
\text { partir } & \text { de } \\
\text { percepciones } & \\
\text { sesgadas del Estado, } \\
\text { redunda en una } \\
\text { especialización } \\
\text { desmarcada } \\
\text { valores. }\end{array}$ \\
\hline
\end{tabular}


sesgadas acerca del del aula.

impacto de estas políticas públicas. Es decir que los actores no parecen observar las consecuencias de las programas $y$ estrategias en el aula.

Indefensión

sistemática de la rectoría del Estado generó una dependencia de la ciudadanía para con los gobernantes, pero al reducirse a su mínima expresión,

produjo una desesperanza

manifiesta en indignación, enojo, miedo o zozobra.

Los contenidos difundidos en los medios de comunicación, en tanto instrumentos de promoción de la rectoría del Estado en materia de Desarrollo Sustentable y gestión política, son diseminados en valores y normas de grupos y sectores a través de discursos y estilos de ciudadanía.

La gestión y La equidad y la administración libertad son temas pública se cristaliza en la propaganda del Estado omnipresente y determinista de la vida pública, privada centrales en la construcción de una pública respalde agenda que el e íntima de la y esferas cívicas. relacionados con subjetivo más que con la calidad de vida.

ndicados demandas están por

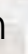

Los estilos de vida orientados desde la óptica del poder de la rectoría del
Gobernanza

temas La ausencia de agenda reconocimientos son propicia en como estudiantes y de docentes una

y identidad apolítica entre que atribuye al Estado la desesperanza adquirida y el fracaso consecuente.

La generación de oportunidades por parte de las políticas públicas del Estado, supone la herencia y el aprendizaje de capacidades no

y siempre correspondientes con las libertades cívicas.

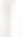
e 
ciudadanía.

Fuente: Elaboración propia

En cierto modo, la encrucijada de la educación superior, a la vez que complejidad, consiste en los efectos de la propaganda del Estado sobre las capacidades de los actores, docentes y estudiantes.

En la medida en que tal proceso es asimilado como hipermetropía, indefensión o habitus va definiendo la gobernanza local.

Es el caso de las IES que, en el contexto de la calidad de los procesos y los productos, está determinada por normas y protocolos que derivan de la administración y la gestión pública (Moser, 2003).

Sin embargo, en el caso de los gobiernos y políticas con base en el establecimiento de una agenda común, la hipermetropía e la indefensión son reducidas a su mínima expresión porque los habitus correspondientes socavan y confinan una agenda más bien sociopolítica.

Por consiguiente, las agendas mediáticas, políticas, civiles, públicas y sociopolíticas son la materialización de la encrucijada del sistema educativa.

Es cierto que las diferencias entre los actores se dirimen en los habitus, pero es en la abstracción de los temas, el debate y los acuerdos en los que el sistema educativo cobra sentido que, en este caso, es la sustentabilidad (Osorio, 2012).

\section{Estado del conocimiento de la cultura laboral}

Los estudios de la cultura laboral advierten que ésta consiste en valores y normas establecidas en el interior de la organización con la finalidad de preservar estructuras y cambiar paradigmas que limiten o promuevan el desarrollo endógeno. De este modo, la cultura laboral que se circunscribe a la obtención de resultados no sólo limita los valores, sino además enaltece la desvalorización de la organización (Tula, 2008: p. 391).

Mendoza y Rositas (2011) advierten que se trata de un ámbito simbólico, el cual se distancia de aspectos técnicos, formativos, administrativos y tecnológicos (p. 12). En ese sentido, mediante análisis de redes, contenido y regresión lineal múltiple encontraron que la cultura laboral es más sinónimo de seguridad que de identidad (p. 25).

Es decir que, la cultura laboral es un escenario en el que los valores y normas explican un universo simbólico de seguridad e identidad, orientando la toma de decisiones con base en las demandas y los recursos inherentes a las organizaciones. Se trata de un "radio social" en el que se edifican identidades dotadas de significados que legitiman las diferencias entre grupos e individuos, pero también se generan y asimilan símbolos de aprendizaje y conocimiento (Páez, 2012: p. 3).

Por consiguiente, la cultura laboral, la identidad, el capital intelectual y social constituyen una realidad organizacional intangible que es de suma importancia para entender la economía basada en la información y el conocimiento. 
A diferencia de la economía clásica en donde prevalece una cultura laboral; tradicional, centrada en el control y el poder, la comunicación unilateral y las relaciones verticales de obediencia y conformidad, la economía moderna un cambio de paradigma.

La sustitución paulatina de la influencia en el lugar del poder, el liderazgo transformación más que la gerencia de mando, la formación colaborativa más que la especialización, la comunicación bidireccional más que unilateral, la apertura al cambio en lugar de la resistencia y la diferencias entre líder y seguidores respecto a la corresponsabilidad, edificaron una cultura laboral centrada en el talento humano, en sus competencias y capacidades.

Porras (2009: p. 39) señala que la cultura laboral en tanto sistema es fundamento para el establecimiento e implementación de programas y estrategias orientados a maximizar las expectativas de los talentos o capital humano. Precisamente, es la cultura laboral una instancia de planificación estratégica centrada en el conocimiento, las propuestas y la responsabilidad.

La cultura labora, en tanto sistema de valores, inicia con el liderazgo vinculado a la comunicación organizacional y ésta como determinante del clima y el capital humano, principalmente en el conocimiento (Charón, 2007: p. 93)

La especificación de la cultura laboral, indicada por valores, normas, representaciones, percepciones, creencias, habilidades, conocimientos, motivaciones e intenciones supone un estudio transversal, exploratorio y no experimental ya que, a diferencia de los estudios financieros, la cultura organizacional está en construcción y postrada en el análisis de las trayectorias de relaciones de dependencia posibles entre las variables revisadas en el estado del conocimiento.

Carreón, Hernández, Bustos y García (2017) demostraron que las políticas de microfinanciamiento no sólo coadyuban en el establecimiento de una cultura del emprendimiento sino, además propician una equidad distributiva entre jefas de familia caficultoras.

Carreón, Hernández, Quintero y García (2017) especificaron un modelo para el estudio de la colaboración organizacional, sugiriendo la inclusión de variables complejas como la adaptabilidad, la recursividad, la disipación y la dinámica para demostrar una estructura factorial exploratorio de cuatro ejes principales en torno a la cultura educativa en una IES del centro de México.

García (2017) propuso un modelo para el estudio de la generación milenaria, considerando su uso intensivo de tecnologías, dispositivos y redes de información, incluyó variables tales como la innovación y la compatibilidad con el emprendimiento, así como ansiedad y adicción en torno al uso del Internet.

García, Bustos y Carreón (2017) infirieron el significado del estigma laboral al establecer categorías de análisis considerando las necesidades y las expectativas de los entrevistados antes de egresar y emigrar a los Estados Unidos de América. La construcción discursiva y narrativa de los futuros migrantes se circunscribió al aprendizaje y la práctica de una técnica que en su lugar de origen se desconoce, pero está bien valorada en el país receptor. A partir de este imaginario y 
representación laboral, los entrevistados develaron un estigma que reduce la importancia del trabajo en México e incrementa el prestigio del trabajo en EU.

García, Carreón y Bustos (2017) plantearon la observación de una cultura laboral excluyente fuera de las organizaciones con fines de lucro como es el caso de las Instituciones de Educación Superior que, en tanto formadoras de talentos, generan una aversión a la equidad, la colaboración y el altruismo. Demostraron la emergencia de una cultura laboral excluyente como lo es el estigma.

García, Carreón y Hernández (2017) establecieron los factores indicativos de una cultura laboral de autocuidado contraria a las culturas organizacionales del equilibrio entre las demandas externas y las capacidades internas, el modelo desarrollado incluyó factores del clima laboral como la cooperación, el aprendizaje y la innovación que explicaron un factor de segundo orden identificado por la literatura como la cultura democrática; liderazgo transformacional, motivación y comunicación bilateral.

Valdés, Quintero y García (2017) generaron un modelo complejo en el que los factores se interrelacionan unos con otros para evidenciar una cultura laboral recursiva que atiende a las relaciones entre las demandas y las capacidades, así como entre las oportunidades y los recursos a fin de anticipar escenarios de colaboración, emprendimiento e innovación.

Sánchez, Quintero y García (2017) establecieron la relación entre la cultura participativa, el liderazgo transformacional, la comunicación y la motivación bilateral. En la medida en que se intensificaban los consensos, las decisiones incluyeron beneficios colectivos como es el caso de la equidad en las remuneraciones, compensaciones y estímulos, pero cuando el proceso era sexista no sólo generó inequidad en los sueldos y las prestaciones sino, además limitó la incorporación de las mujeres a los puestos decisorios.

\section{Especificación de un modelo para el estudio de la cultura laboral}

Un modelo es una representación de supuestos teóricos, conceptuales y hallazgos empíricos desde los que es posible establecer las trayectorias de relaciones de dependencia entre las variables revisadas en el estado del conocimiento. A partir de las premisas centrales de las teorías, se modelan las correlaciones entre las variables con la finalidad de encontrar el sistema implícito o latente que explica un fenómeno.

En tal sentido, un modelo especificado sugiere el contraste o prueba empírica de relaciones de dependencia entre las variables que han sido identificadas y utilizadas para explicar un proceso o fenómeno, pero debido a que cada contexto y muestra es diferente, el modelo propuesto se especifica hasta agotar las posibles trayectorias de relaciones entre las variables, o bien, reconocer sus correlaciones espurias o multicolineales, principales límites de los modelos.

Por consiguiente, el modelo que se propone incluye siete hipótesis, trayectorias y relaciones de dependencia que explicarían la corresponsabilidad entre líderes y seguidores en el marco de la cultura laboral adhocrática o gobernanza organizacional ante contingencias, demandas e incertidumbre del entorno. 
En la primera trayectoria que va de la contingencia a los valores, las microrganizaciones, en su afán de sobrevivir, responden con principios de colaboración, solidaridad y cooperación, pero se enfrentan a imponderables que limitan sus oportunidades y reducen sus capacidades a una mínima expresión (hipótesis 1).

Es por tal motivo que en la segunda trayectoria que va de las contingencias a las percepciones, las microempresas desarrollan una hipermetropía que consiste en el procesamiento de información de un modo tal que asumen las crisis globales como procesos que repercutirán sólo en las trasnacionales, afectando mínimamente su realidad, o bien, procesos locales como inundaciones que, en caso de presentarse, no afectarán prolongadamente su dinámica empresarial y comercial (hipótesis 2).

No obstante, los valores cooperativos y la hipermetropía son insuficientes para afrontar las crisis globales o las vicisitudes locales cuando la organización tiene la misión y la visión de crecer y posicionarse en el mercado. Por consiguiente, desarrollarán un conocimiento con base en ensayos de aciertos y errores desde el que establecerán una planificación y alianza estratégica con otras organizaciones pequeñas o medianas ya no sólo para subsistir en el mercado, sino para acrecentar sus fronteras (hipótesis 3).

En el proceso de crecimiento, expansión y posicionamiento de las organizaciones, el aprendizaje de habilidades es fundamental para cubrir las demandas de trasnacionales que las han subordinado. Es por tal motivo que el conocimiento práctico o tácito es indispensable para la función subsidiaría o maquiladora de la organización que busca crecer abastecimiento de recursos y dotando de capital humano a otras organizaciones de mayor envergadura (hipótesis 4).

Sin embargo, la diferencia sustancial entre micro, pequeñas, medianas y grandes empresas, en el sentido de la cultura laboral radica en toma de decisiones con base en estructuras verticales $u$ horizontales de mando y obediencia, comunicación unilateral o bidireccional en su clima de relaciones y tareas, así como estilos de dirección coercitiva o persuasiva. Es el caso del liderazgo tradicional que se desarrolla en mipymes en relación con el liderazgo transformacional que se gesta en las organizaciones de mayor tamaño (hipótesis 5).

Incluso, en los casos de las grandes organizaciones, la toma de decisión o intención no siempre es responsabilidad del líder, sino que en la planificación y las alianzas estratégicas participan otros actores que nutren el clima laboral y con ello aportan nuevas formas de cultura organizacional. La diferencia entre organizaciones que ajustan sus decisiones a las contingencias y las organizaciones que se anticipan a ellas supone una gestión de conocimiento y una administración de talentos con recursos y capacidades indispensables para la producción del conocimiento y la transformación del mercado (hipótesis 6).

Empero, las contingencias ambientales, desastres climáticos, crisis ecológicas o catástrofes naturales propicia liderazgos y seguidores corresponsables con su entorno. Por consiguiente, las organizaciones deben emprender e innovar en sus procesos internos para anticipar escenarios desfavorables, así como desarrollar a 
sus talentos promoviendo relaciones libres de violencia, autocuidado, cooperación, empatía, compromiso, satisfacción y felicidad (hipótesis 7).

A partir de esta modelo la pregunta que guía la presente investigación es: ¿Las relaciones teóricas revisadas en la literatura y el estado del conocimiento entre los indicadores de la cultura organizacional se ajustarán a los datos observados en el estudio empírico?

La hipótesis nula que responde a la cuestión es: En un contexto de contingencias galopantes, las organizaciones deben anticipar escenarios desfavorables, orientando sus recursos y capacidades, así como formando talentos que incidan en sus procesos y productos a partir de criterios de sostenibilidad, calidad y gobernanza. Por consiguiente, las relaciones teóricas, conceptuales y empíricas se ajustarán a las relaciones ponderadas en el estudio empírico.

Sin embargo, aún y cuando las organizaciones buscan anticipar escenarios imponderables, sus contextos locales no siempre están vinculados con el ámbito global. De este modo, la literatura revisada y el estado del conocimiento de los hallazgos expuestos, sólo explican unas trayectorias de relaciones de dependencia posibles, pero no se ajustarán a los datos observados en el estudio empírico.

\section{MÉTODO}

Diseño. Se realizó un estudio no experimental, trasversal y exploratorio.

Muestra. Se llevó a cabo una selección no probabilística de 320 docentes, estudiantes y administrativos de una Institución de Educación Superior de la Ciudad de Cuernavaca, Morelos (Centro de México) perteneciente a la ANFECA.

Instrumento. Se utilizó la Escala de Cultura Organizacional de Carreón (2016) la cual incluye cuatro dimensiones relativas a hipermetropía -expectativas de despreocupación por las políticas educativas-, indefensión -expectativas de desesperanza por la evaluación docente-, habitus -expectativas de disposición por la acreditación de curriculums- y gobernanza -expectativas de decisión en torno a la certificación académica-. Cada ítem incluye cinco opciones de respuesta que van desde "nada probable" hasta "muy probable".

Procedimiento. Se utilizó la técnica Delphi para la homogenización de conceptos incluidos en los reactivos. Antes de la encuesta, se garantizó la confidencialidad por escrito y se informó que los resultados del estudio no afectarían el estatus académico o laboral de la muestra. La información de procesó en el Paquete Estadístico para Ciencias Sociales (SPSS versión 20). Se estimó la confiabilidad con el parámetro alfa de Cronbach, la adecuación con el estadístico KMO, la esfericidad con la prueba de Bartlett, la validez con pesos factoriales -análisis factorial exploratorio de componentes principales con rotación varimax-, el ajuste con chi cuadrada, GFI y CFI, así como el residual con RMSEA.

\section{RESULTADOS}

La confiabilidad del instrumento general (alfa $=0,772$ ) y de las subescalas de hipermetropía (alfa = 0,712 y 30\% de la varianza total explicada), indefensión (alfa 
$=0,790$ y $27 \%$ de la varianza total explicada), habitus (alfa $=0,753$ y $23 \%$ de la varianza total explicada) y gobernanza (alfa $=0,716$ y $20 \%$ de la varianza total explicada) evidencian la consistencia interna de los factores de primer y segundo orden que fueron establecidos mediante el análisis factorial exploratorio de componentes principales con rotación varimax (véase tabla 3).

Tabla 3. Descriptivos, confiabilidad y validez del instrumento

\begin{tabular}{|c|c|c|c|c|c|c|c|c|}
\hline Clave & Ítem & $M$ & $\mathrm{DE}$ & Alfa & F1 & F2 & F3 & $F$ \\
\hline & $\begin{array}{ll}\text { Subescala } & \text { de } \\
\text { hipermetropía }\end{array}$ & & & 0,712 & & & & \\
\hline HP1 & $\begin{array}{l}\text { Las políticas educativas } \\
\text { incidirán sólo en el nivel } \\
\text { básico }\end{array}$ & 1,34 & 0,83 & 0,734 & 0,321 & & & \\
\hline HP2 & $\begin{array}{l}\text { El recorte presupuestal } \\
\text { afectará sólo a las } \\
\text { instituciones privadas }\end{array}$ & 1,21 & 0,42 & 0,782 & 0,347 & & & \\
\hline HP3 & $\begin{array}{l}\text { Los lineamientos políticos } \\
\text { influirán solo en las } \\
\text { instituciones de provincia }\end{array}$ & 1,20 & 0,56 & 0,734 & 0,328 & & & \\
\hline \multirow[t]{2}{*}{ HP4 } & $\begin{array}{l}\text { Los reconocimientos son } \\
\text { exclusivos de la } \\
\text { universidad nacional }\end{array}$ & 1,27 & 0,67 & 0,715 & 0,380 & & & \\
\hline & $\begin{array}{l}\text { Subescala de } \\
\text { indefensión }\end{array}$ & & & 0,790 & & & & \\
\hline IF 1 & $\begin{array}{l}\text { La evaluación docente } \\
\text { afectará la formación } \\
\text { de profesionistas }\end{array}$ & 1,05 & 0,81 & 0,746 & & 0,325 & & \\
\hline IF2 & $\begin{array}{l}\text { La evaluación docente } \\
\text { incidirá en los planes } \\
\text { curriculares }\end{array}$ & 1,46 & 0,93 & 0,765 & & 0,374 & & \\
\hline IF3 & $\begin{array}{l}\text { La evaluación docente } \\
\text { propiciará conflictos } \\
\text { internos }\end{array}$ & 1,37 & 0,82 & 0,792 & & & & \\
\hline \multirow[t]{2}{*}{ IF4 } & $\begin{array}{l}\text { La evaluación docente } \\
\text { dividirá a los estudiantes }\end{array}$ & 1,27 & 0,32 & 0,761 & & 0,319 & & \\
\hline & Subescala de habitus & & & 0,753 & & & & \\
\hline HB1 & $\begin{array}{l}\text { La acreditación } \\
\text { curricular influirá en la } \\
\text { formación docente }\end{array}$ & 1,06 & 0,46 & 0,726 & & & 0,317 & \\
\hline HB2 & $\begin{array}{lr}\text { La } & \text { acreditación } \\
\text { curricular } & \text { determinará } \\
\text { las } & \text { competencias }\end{array}$ & 1,93 & 0,21 & 0,715 & & & 0,373 & \\
\hline
\end{tabular}


docentes

HB3 La acreditación
curricular repercutirá en
las
laborales

HB4 La

$1,38 \quad 0,36 \quad 0,795$

0,368

GZ1 La certificación docente

GZ2 La matrícula estudiantil

Gz3 La certificación de

acreditación

curricular incidirá en las

prácticas profesionales

\section{Subescala gobernanza}

$\begin{array}{lll}1,02 & 0,67 & 0,732\end{array}$ condicionará la elección de sus representantes dependerá de la certificación de la infraestructura plazas orientará las líneas de investigación

GZ4 La certificación de $1,97 \quad 0,13 \quad 0,789$

\section{$1,31 \quad 0,46 \quad 0,706$}

0,716

planes de estudio facilitará el concurso de plazas

\section{$1,25 \quad 0,89 \quad 0,758$}

Método de extracción: Componentes principales -análisis factorial exploratorio con rotación varimax-. Adecuación y esfericidad $\{x 2=436,21$ (57gl) $p=0,000$; $\mathrm{KMO}=0,890 \mathrm{~J} . \mathrm{F} 1=$ Hipermetropia $(30 \%$ de la varianza total explicada), $\mathrm{F} 2=$ Indefensión ( $27 \%$ de la varianza total explicada), $\mathrm{F} 3=$ Habitus $(23 \%$ de la varianza total explicada), F4 0 Gobernanza ( $20 \%$ de la varianza total explicada). Cada ítem se responde con alguna de cinco opciones que van desde $0=$ "nada probable" hasta 4 = "muy probable".

Fuente: Elaborada con los datos del estudio

Respecto a la estructura de cuatro factores, la adecuación y esfericidad $\lceil\times 2=$ 436,21 (57gl) $p=0,000 ; \mathrm{KMO}=0,890 \mathrm{~J}$ permitieron estimar tos pesos factoriales para establecer los factores -correlaciones superiores a 0,300-. Una vez establecida la validez, se ponderaron las correlaciones entre los factores (véase tabla 4).

Tabla 4. Correlaciones entre los factores

\begin{tabular}{llll}
\hline & Hipermetropía Indefensión Habitus & Gobernanza \\
\hline Hipermetropía & 1,000 & \\
Educativa & & \\
(HE) & & \\
\hline
\end{tabular}




\begin{tabular}{lll}
\hline Indefensión & $0,324^{*}$ & 1,000 \\
Académica &
\end{tabular}

(IA)

$\begin{array}{llll}\text { Habitus } & 0,325^{* *} & 0,310^{*} & 1,000 \\ \text { Formativos } \\ \text { (HF) }\end{array}$

(HF)

Gobernanza $\quad 0,376^{* * *} \quad 0,326^{* *} \quad 0,307^{*} \quad 1,000$ Institucional

(GI)

$* p<0,01 ; * * p<0,001 ; * * * p<0,0001$

Fuente: Elaborada con los datos del estudio

La estructura de relaciones de dependencia entre los cuatro factores y sus indicadores muestra valores cercanos a cero. Es decir que la cultura organizacional, en tanto estructura de percepciones relativas a las demandas y los recursos de la institución, incluye factores que explican las expectativas de los actores ante las políticas evaluativas, acreditadoras y certificadoras.

Una vez establecidos los factores y las asociaciones entre ellos, se procedió a estimar sus trayectorias reflejantes en un modelo estructural (véase Figura 1).

Figura 1. Modelo estructural de trayectorias de relaciones

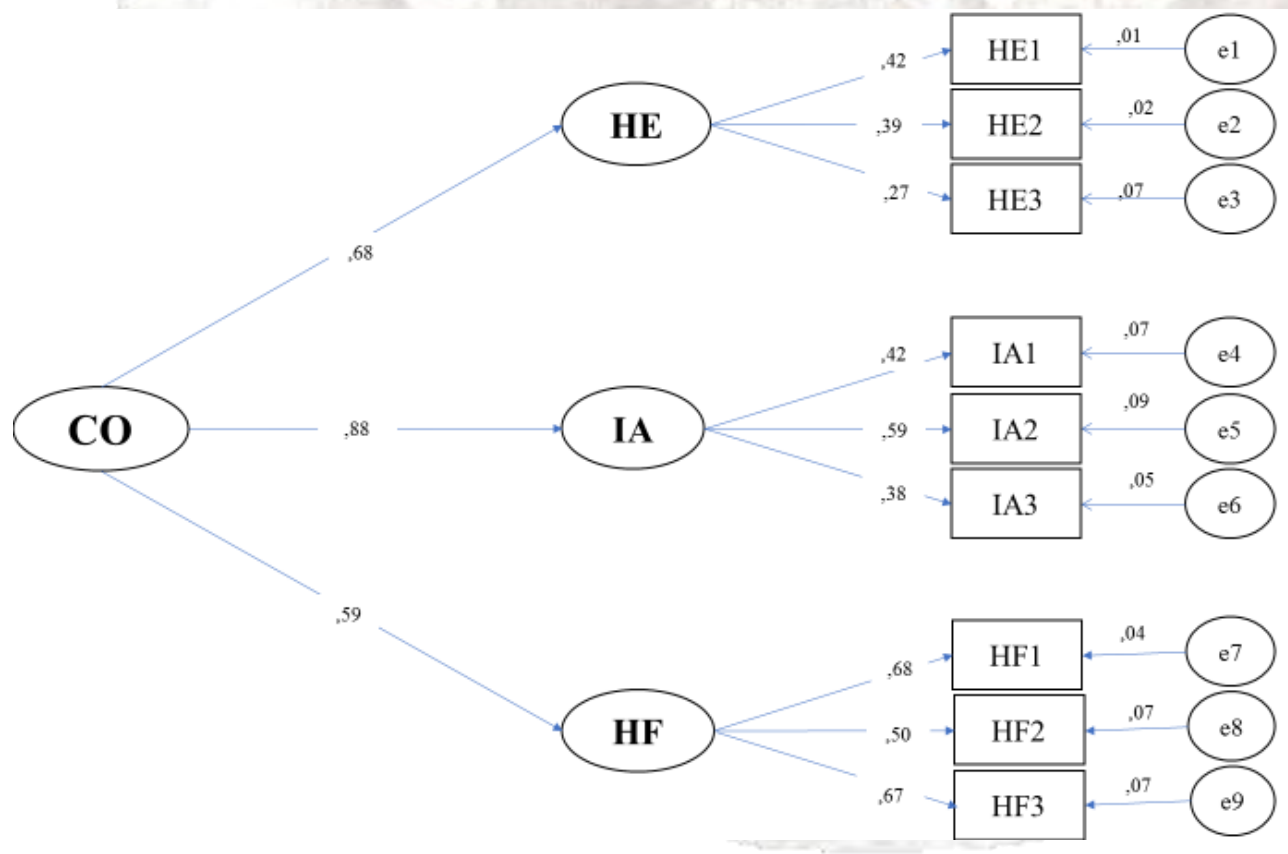

Fuente: Elaborada con los datos del estudio

Los parámetros de ajuste y residual $[X 2=135,25$ (35gl) $p=0,000 ; \mathrm{GFI}=0,990 ; \mathrm{CFI}=$ 0,975; RMSEA = 0,003

\section{DISCUSIÓN}

El aporte del presente trabajo al estado de la cuestión radica en la contrastación de un modelo para el estudio de la cultura laboral en una IES del centro de México. Se trata de una estructura de tres factores prepodnerantes en la que el 
sesgo perceptual de las consecuencias de políticas educativas, la desesperanza ante la evaluación, acreditación y certificación, así como las disposiciones hacia la formación profesional suponen la conformación de un sistema de valores y normas relativas a la gestión y la administración del conocimiento

Empero, el porcentaje de varianza total explicada de los tres factores que conforman el modelo parece sugerir la inclusión de otros que la literatura recupera como formación colaborativa o cultura de emprendimiento e innovación.

La cultura organizacional a menudo es considerada y por lo tanto medida como un continuo de valores y normas establecidos en la institución como respuesta a las demandas del mercado o del Estado.

García et al., (2013) estimó la cultura laboral a partir del compromiso asumido por los talentos con respecto a las demandas sociales y los recursos disponibles. Encontraron que las normas familiares y gremiales incidieron en la atención y la calidad de los servicios de salud pública.

En otro estudio relativo a la cultura de éxito, García (2004) demostró la incidencia de las variables perceptuales sobre la eficacia organizacional. A partir de un modelo estructural en el que incluyó a las expectativas como factores exógenos a las normas y valores organizacionales, explicó la influencia de la cultura de éxito con respecto al emprendimiento, la innovación y la competitividad.

Sin embargo, la cultura organizacional también supone factores endógenos a la institución que podrían estar incidiendo en la toma de decisiones y en el desempeño de los actores.

De este modo es necesario introducir como variables endógenas a la empatía, el compromiso, la satisfacción y la corresponsabilidad como indicadores de una cultura laboral menos dependiente del liderazgo que supone hipermetropía y habitus, así como los síntomas de sus adherentes -indefensión y gobernanza-.

En el modelo será posible observar que a medida que el liderazgo se intensifica, aumenta la hipermetropia y el habitus en torno a la consecución de objetivos y logro de metas, pero también será posible advertir la emergencia de la desesperanza de seguidores, ya que éstos pueden reducir sus expectativas de beneficios y aumentar sus percepciones de riesgo con respecto a las demandas del líder y la escasez de prestaciones.

\section{CONCLUSIÓN}

El objetivo del presente trabajo fue contrastar un modelo para el estudio de la cultura laboral en IES del centro de México, considerando los factores que la literatura cita como los hegemónicos ante políticas de evaluación, certificación y acreditación de la calidad de los procesos y los productos. Se recomienda la inclusión de otros factores revisados en la literatura, así como la prueba empírica del modelo en otros escenarios académicos y laborales. 


\section{REFERENCIAS}

Austrolakis, N. (2013). Desafiando la economía convencional: el paradigma ético del desarrollo. Revista Problemas del Desarrollo, 175 (44), 33-53

Carreón, J., Hernández, J., Bustos, J. M. y García, C. (2017). Políticas de fomento empresarial y sus efectos sobre las percepciones de riesgo en caficultores de Xilitla, San Luis Potosí, centro de México. Poiesis, 32, 33-51

Carreón, J., Hernández, J., Quintero, M. L. y García, C (2017). Confiabilidad y validez de un instrumento que mide la colaboración organizacional en una universidad pública de Huehuetoca, centro de México. Invurnus, 12 (2), 9-17

Charón, L. (2007). Importancia de la cultura organizacional para el desarrollo de un sistema de gestión de calidad. Ciencia, 5, 87-95

Corral, V. y Pinheiro, J. (2009). Environmental psychology with a latinamerican taste. Journal of Environmental Psychology, 29, 366-374

Corraliza, J. (2001). El comportamiento humano y los problemas ambientales. Estudios de Psicología, 22, 5-9

Embar, A. (2002). Ciberterrorism. American behavioral Scientist, 45 (6), 1033-1043

García, C. (2004). Una modelación de los determinantes de la eficacia organizacional." Revista Internacional de Psicología, 5 (1), 1-12

García, C. (2017). Modelo de millennials emprendedores. Cambios \& Permanencias, 8 (2), 379-395

García, C., Bustos, J. M. y Carreón, J. (2017). Dimensiones exploratorias del estigma social y laboral. Un estudio Delphi con estudiantes de pre-grado. Eureka, 14 (1), 5568

García, C., Carreón, J. y Bustos, J. M. (2017). Los estudios de la migración laboral: estructura factorial exploratoria del estigma laboral. Eureka, 14 (2), 173-184

García, C., Carreón, J. y Hernández, J. (2017). Límites de los modelos de la salud ocupacional. Estudios de la adhesión al tratamiento del asma en trabajadoras migrantes adultos mayores del Estado de México. Visión Gerencial, 16 (1), 103-118

García, C., Carreón, J., Bustos, J., Bautista, M., Méndez, A. y Morales, M. (2013). Compromiso laboral del trabajo social en el sector salud. Revista Electrónica de Medicina, Salud y Sociedad, 4 (1), 39-58

Leal, A. (2014). De pueblo a sociedad civil: el discurso polífico del sismo de 1985. Revista Mexicana de Sociología, 76 (3), 441-469

Mendoza, J. y Rositas, J. (2011). Similitudes y diferencias en la cultura laboral mexicana: elementos compartidos en organizaciones de diferente desempeño. Innovaciones de Negocios, 8 (15), 11-41

Moser, G. (2003). La psicología ambiental en el siglo 21: el desafío del desarrollo sustentable. Revista de Psicología de la Universidad de Chile, 12, 11-17

Osorio, J. (2012). Estado, biopoder y exclusión. Análisis desde la lógica del capital. Barcelona: Anthropos 
Ostron, E. (2014). Más allá de los mercados y los estados: gobernanza policéntrica de sistemas económicos complejos. Revista Mexicana de Sociología, 76, 15-70

Páez, J. G. (2012). La gobernabilidad y la cultura laboral en el entorno universitario. Una perspectiva cualitativa. Aposta, 52, 1-27

Porras, N. R. (2009). Elementos básicos para el análisis de la cultura de las organizaciones desde la psicología. Tesis Psicológica, 4, 36-51

Rohrmann, B. (2000). A socio psychological model for analyzing risk communication process. Australian Journal of Disaster and Trauma Studies, 2, 1-9

Sánchez, A., Quintero, M. L. y García, C. (2017). Complejización de un modelo de dirección sexista laboral. Ciencias Sociales, 3 (4), 24-37

Tula, F. (2008). Time is money: optimización, identidad y cultura laboral en la sociedad deseada. Scientia e Studia, 6 (3), 389-408

Valdés, O., Quintero, M. L. y García, C. (2017). Complejización de un modelo de cultura laboral migrante. Doxa, 7 (13), 66-78

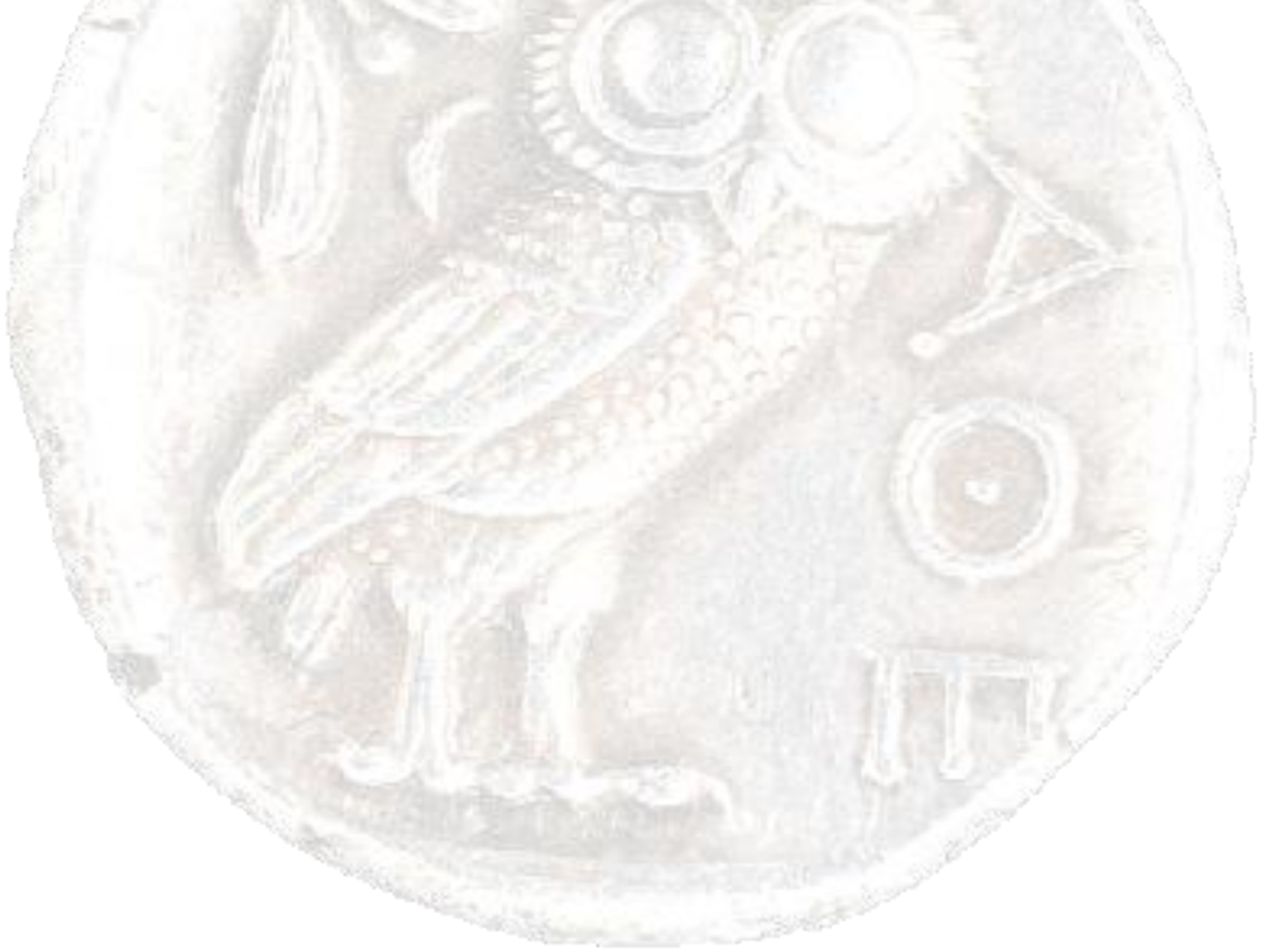

